\title{
The Limit Decision Problem and Four-Dimensionalism*
}

\begin{abstract}
I argue that medieval solutions to the limit decision problem imply fourdimensionalism, i.e. the view according to which substances that persist through time are extended through time as well as through space, and have different temporal parts at different times.
\end{abstract}

\section{Keywords}

Permanent and successive entities - three- and four-dimensionalism temporal parts - limit decision problem - location

Four-dimensionalism is the view according to which substances are extended through time as well as through space; just like a substance is thought to be extended through space by having different spatial parts at different places, four-dimensionalists believe that substances are extended through time by having different temporal parts at different times. Boosted by a growing battery of arguments, four-dimensionalism is presumably enjoying its Golden Age, and has forced his foes on the back foot ${ }^{1}$. Somehow unsurprisingly, things used to be different some eight hundred years ago, when, with the possible exception of Bonaventure, the overwhelming majority of scholastic philosophers maintained the rival view - nowadays called three-dimensionalism - according to which substances persist through time without having temporal parts ${ }^{2}$. However, it is not unusual that philosophers commit themselves to doctrines which they deny. In this paper, I argue that standard medieval accounts of change - standard solutions to the so-called limit decision problem in particular - trigger an argument that ultimately leads to the four-dimensionalist view of persistence.

\footnotetext{
* I am grateful to Claudio Calosi, Ilaria Canavotto, Frédéric Goubier, Can Loewe, Paolo Natali, Magali Roques, Cecilia Trifogli and to the members of the audience of the conference Limit Decision Problems: Medieval and Contemporary Perspectives in Berlin for useful questions and fruitful comments on earlier drafts of this paper.

${ }^{1}$ For a sympathetic review of the arguents in favour of four-dimensionalism, I refer the reader to T. Sider, Four-Dimensionalism: An Ontology of Persistence and Time (Oxford 2001).

2 R. Cross, "Four-Dimensionalism and Identity Across Time: Henry Ghent vs. Bonaventure," Journal of the History of Philosophy 27 (1999), 393-414.
} 
The paper is in two main parts. The first one sets the stage by presenting the limit decision problem and the standard solutions adopted by the scholastics during the period when controversies concerning this problem flourished the most, i.e. during the thirteenth and fourteenth centuries. Building on a tension in these standard solutions raised by Paul Vincent Spade, the second part of the paper argues that those standard solutions make persistence without temporal parts impossible. The paper concludes then that if substances persist, they so by having temporal parts.

Medieval Solutions to the Limit Decision Problem

\subsection{The Limit Decision Problem}

A light suddenly switches off. Consider the instant $t$ at which the switching occurs. Before $t$, the light is on, after $t$, it is off, i.e. not on. However at the instant $t$, is it still on or already off? In principle, four options offer themselves:

(1) At $t$, the light is on.

(2) At $t$, the light is off.

(3) At $t$, the light is neither on nor off.

(4) At $t$, the light is both on and off.

Many philosophers have long thought that options (3) and (4) must be excluded, for they go against the law of non-contradiction, the law of excluded middle or the concept of negation itself.

Options (3) and (4) excluded, one may think that there is no real problem here: when a light switches from on to off, there will be an instant $t_{1}$ at which it is on, immediately followed by another instant $t_{2}$ at which is off. In that case, a choice between (1) and (2) seems not to be so pressing after all. However, this easy solution is excluded if one thinks that time is continuous. Indeed, if we assume that time is continuous, between any

${ }^{3}$ The following account of the Limit Decision Problem and its treatment is mainly based on G. Priest, In Contradiction. A Study of the Transconsistent (Dordrecht 1987): N. Kretzmann, "Incipit/Desinit," in Matter and Time, Space and Motion, eds. J. Machamer and P. Turnbull (Columbus 1976), 101-136; S. Knuuttila and A. I. Lehtinen, "Change and Contradiction: A Fourteenth Century Controversy," Synthese 40 (1979), 189-207; P. Spade, "How to Start and Stop. Walter Burley on the Instant of Transition," Journal of Philosophical Research 19 (1994), 193-221; A. de Libera, "La problématique de l' instant du changement' au XIIÌ̀me siècle: contribution à l'histoire des Sophismata Physicalia," in Studies in medieval Natural Philosophy, ed. S. Caroti (Firenze 1989) and N. Strobach, The Moment of Change. A Systematic History in the Philosphy of Space and Time (Dordrecht 1998). 
two instants $t_{1}$ and $t_{2}$ there will always be a third instant $t_{3}$ : no instant can immediately follow another.

In light of the assumption that time is continuous, the choice between option (1) and option (2) becomes indeed pressing. In making such a choice, we are choosing whether $t$ is the last instant at which the light is on or the first instant at which it is off. And given that there cannot be immediately adjacent instants, there cannot be both a last instant at which the light is on and a first instant at which it is off. Hence, we are choosing whether

(1') there is a last instant at which the light is on and no first instant at which the light is off

or

(2') there is no last instant at which it is still on and a first instant at which it is off.

This result allows us to understand why this problem is sometimes called the limit decision problem. The problem can be equivalently described in terms of the kind of temporal limits that a state - such as the light's being on - has. Let us introduce a bit of technical terminology, and distinguish between extrinsic/open and intrinsic/closed temporal limits, and in particular let us say that a state is intrinsically limited at its beginning its first limit is closed - if and only if it has a first instant; otherwise it is extrinsically limited at its beginning - its first limit is open. Let us also say that a state is intrinsically limited at its end - its last limit is closed - if and only if it has a last instant; otherwise it is extrinsically limited at its end its last limit is open. Choosing between option (1) and (2) means choosing whether

(1") the light's being on is intrinsically limited at its end - its last limit is closed.

or

(2") the light's being on is extrinsically limited at its end - its last limit is open.

Square brackets have been conveniently employed to represent a state's being extrinsically or intrinsically limited at one hand, where square 
brackets point towards a state that is intrinsically limited. For example, we will represent the fact that the light's being on is intrinsically limited at its end, i.e. option (1), as follows:

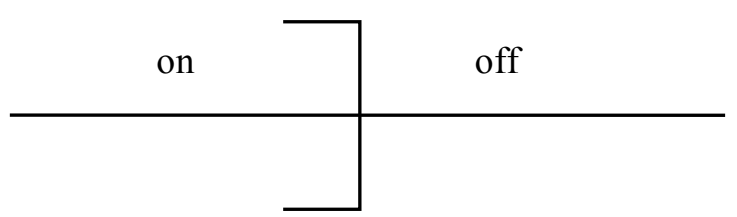

Figure 1. The light's being on is intrinsically limited at its end.

So it seems that we should indeed make a choice between option (1) and option (2). However, there seems to be no reason to prefer one in spite of the other. If there are no clear grounds on which the choice can be made, the choice will end up being arbitrary, and many find that this kind of arbitrariness is, when dealing with philosophical problems, completely out of place ${ }^{4}$. Some philosophers feel then prompted to find reasons to prefer one of the first two options over the other, while others think that no such reason can be found, and take this result as reason to take the other two options more seriously ${ }^{5}$.

\subsection{Medieval Solutions to the Limit Decision Problem: the Distinction between Permanent and Successive Entities}

The limit decision problem - which is, for obvious reasons, also called the problem of the instant of change - is known and discussed at least since Aristotle's Physics and Sofistical Refutations ${ }^{6}$. However the context in the history of philosophy in which it has been most hotly discussed is arguably the Latin scholastics of the thirteenth and fourteenth century, when the relevant Aristotelian texts made their reappearance in the Latin world after their diaspora through the translatio studiorum. Scholastics processed the problem and, in the footsteps of Aristotle, or at least of the Latin Aristotle, gave it a distinctive reading.

\footnotetext{
${ }^{4}$ This point is nicely put forward in Priest, In Contradiction.

${ }^{5}$ For a summary of the solutions to the limit decision problem adopted during the last decades, see Strobach, The Moment of change, part II.

${ }^{6}$ For an overview of the ancient debate on the limit decision problem, see Strobach, The Moment of Change, part I, ch. 1 and 2.
} 
Most medieval solutions to the problem of the instant of change share a common default setting. First, generally ${ }^{7}$ they reject options (3) and (4). Second, they do not make a choice between option (1) and option (2) that applies to all possible cases of change, but rather think that both options apply in different cases.

If one wants to understand what those different cases are, the most important distinction to be introduced is certainly the distinction between permanent and successive entities, which I will explain in this section, and apply in the next section to the limit decision problem.

The distinction between permanent and successive entities has its roots in Aristotle's Physics and, through Averroes commentaries, became a topos of medieval metaphysics ${ }^{8}$. The distinction, as it appears through the history of medieval philosophy, is of central importance for the solution of the limit decision problem as well as for other important contexts, such as the ones dealing with the relation between God on the one hand and space and time on the other'.

The distinction is nicely introduced and applied to the limit decision problem by Walter Burley in his De Primo et Ultimo Instanti. Given that later we will analyse an argument originally put forward against Burley's view on the limit decision problem, it will be a good starting point to see how Burley himself introduces the distinction. The relevant passage reads:

With respect to the first point, you must know that there is a difference between a permanent thing and a successive one. For a permanent thing, speaking about a permanent thing in general, is one for which it is not inconsistent from the nature of the thing to have all [its] parts simultaneously. And a successive thing is one for which it is inconsistent from the nature of the thing to have all its parts simultaneously. Indeed it belongs to its nature that it have an earlier and another, later one. And when the earlier part exists, the other part does not exist. For a stone is a permanent thing, because it is not inconsistent for a stone to have all its parts simultaneously in the same measure. But a day, and a week, and so on, are successive

\footnotetext{
${ }^{7}$ With the notable exception of Quasi-Aristotelianism. See N. Kretzmann, "Continuity, Contrariety, Contradiction, and Change," in Infinity and Continuity in Ancient and Medieval Thought, ed. N. Kretzmann (London, 1982), 270-296 and P. V. Spade, "QuasiAristotelianism," in Infinity and Continuity, 297-307.

${ }^{8}$ A. de Libera, "La problématique de l'instant du changement", 51-52 and R. Pasnau, Metaphysical Themes 1274-1671 (Oxford, 2011), ch. 18.

${ }^{9}$ Pasnau, ibid. and R. Pasnau, "On Existing All at Once," in God, Eternity, and Time, ed. C. Tapp (Ashgate 2011), 11-28.
} 
things because it is inconsistent for them to have all their parts simultaneously. For it is inconsistent with a day that when it is the first hour, it is the third [hour]. ${ }^{10}$

Burley says that successive things are by nature such that they have earlier and later parts. A day, for example, is such that it has a first and a third hour. Earlier and later parts are such that they cannot be had simultaneously (or that they cannot be simultaneous with each other). Indeed, when it is the first hour, it is not the third hour, and vice versa. On the other hand, permanent things are by nature such that they can have all their parts simultaneously (and therefore have no earlier and later parts, which must be had at different times). Burley mentions the example of a stone, the nature of which allows it to have all its parts - the physical particles that make up the stone - at the same time.

A contemporary philosopher can hardly resist the temptation to see here in play a distinction she is familiar with, i.e. the distinction between endurance and perdurance. Endurance and perdurance are notions invoked nowadays to explain how things persist through time, or in other words, how is it possible that the same thing exists at different times. On the one hand, something perdures if and only if it persists by having different temporal parts at different times. On the other hand, something endures if and only if it persists by being wholly present at different times ${ }^{11}$. A contemporary philosopher will be tempted to see a parallelism between Burley's notion of "earlier and later parts" and the contemporary notion of a temporal part, as well as between Burley's notion of "having all parts simultaneously" and the contemporary notion of being wholly present.

\footnotetext{
${ }^{10}$ Here I quote Paul Vincent Spade's translation of Burley's text that can be found in his "How to Start and Stop," 199. The original text taken from Shapiro's edition reads: "Circa primam est sciendum quod differentia est inter res permanen- tem et successivam, quoniam res permanens, communiter loquendo de re permanente, est illa cui non repugnat ex natura rei habere omnes partes simuL Et res successiva est illa cui repugnat ex natura rei habere omnes suas partes simul; ymo est de natura sui quod habeat unam per temporem, et aliam posteriorem, et quando pars prior est, pars posterior non est. Lapis enim est res permanens, quia lapidi non repugnat habere omnes partes simul in eadem mensura. Sed dies et septimana, et sie de aliis, sunt res successive, quia eis repugnat habere omnes partes suas simul. Repugnat enim diei quod quando est hora prima quod sit tertia. Intelligendum ergo est per rem permanentem, illud cuius omnes partes sunt simul, vel cui non repugnat habere omnes suas partes simul." See H. and C. Shapiro, "De Primo et Ultimo Istanti des Walter Burley," Archiv für Geschichte der Philosophie 47 (1965), 157-173.

${ }^{11}$ See T. Sider, Four-Dimensionalism and D. K. Lewis, On the Plurality of Worlds (Oxford, 1986), 199.
} 
One of the central debates in contemporary metaphysics is the one concerning the way in which substances persist through time. Do they persist by enduring or by perduring? Those who think that substances endure - are wholly present at different times - are called threedimensionalists, or also endurantists, whereas those who think that substances perdure - have different temporal parts at different times are called four-dimensionalists, or also perdurantists. Threedimensionalists believe that substances endure. Yet, they may - and often do - think that other entities, such as intervals of time or events, persist by perduring, for an event may be composed by different phases and an interval of time by different instants, which count as temporal parts of the event and the interval, respectively. Given that Burley puts forward a stone as an example of a permanent thing, and a day as an example of a successive thing, the contemporary philosopher will be tempted to identify Burley - together with the majority of its contemporaries which do, or would, offer similar examples - as a three-dimensionalist.

These parallelisms and identifications have indeed been proposed and endorsed by several contemporary scholars, and I add myself to that list $^{12}$.

\subsection{Medieval Solutions to the Limit Decision Problem: the Scholastics on the Temporal Limits of Permanent and Successive Entities}

Now that the distinction between permanent and successive entities has been introduced, let us see how the scholastics applied it to the limit decision problem.

Recall that the limit decision problem has to do with the temporal limits of entities - such as the being off of a light - and in particular with the question of whether those limits are open or closed. In that context, the distinction between permanent and successive entities comes in because most medieval scholars though that whether an entity has open or closed limits is primarily dependent on whether the entity is permanent or successive.

The so-called common theory, which was seen by medieval scholars as the Aristotelian theory, claims that the temporal limits of permanent entities

\footnotetext{
12 See in particular R. Cross, "Four-Dimensionalism and Identity Across Time" and A. Wood, "Mind the Gap? The Principle of Non-Repeatability and Aquinas' Account of the Resurrection," Oxford Studies in Medieval Philosophy 3 (2015), 99-127. On the other hand, a more careful attitude would suggest more investigation on the distinction between permanent and successive things before subscribing to these parallelisms and identifications. However, such an investigation is still lacking in the literature and goes beyond the scope of this paper.
} 
are both closed, whereas the temporal limits of successive entities are both open ${ }^{13}$. The scholastics proposed further distinctions in order to specify whether a state such as the light's being on counted as permanent and successive. However, they did not think that this kind of limit assignment held for states only. They though that every permanent entity has both limits closed and every successive entity has both limits open. So, for example, they think that permanent entities such as human beings and stones have a first and a last instant, whereas successive things such as intervals of time do not. Probably we can safely conceive of a human being as having a first instant, or as having her or his first limit closed, as equivalent to the claim that a state, namely the existence of the human being, has a first instant, or has its first limit closed.

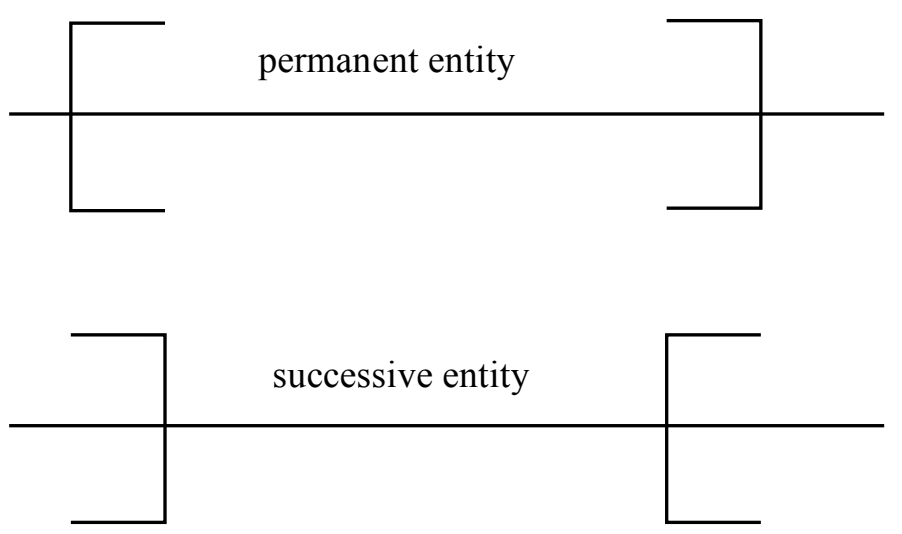

Figure 2. The so-called common theory about the limit decision problem.

The common theory dominated almost unrivalled for a good part of the thirteenth and fourteenth centuries. However, an impressive number of other options are discussed and, with the passage of time, endorsed as well ${ }^{14}$. It is not my aim here to enter into the question of what historic and theoretical reasons have pushed medieval authors to subscribe to the common theory or variations thereof. What is relevant for our aims is that, with the notable exceptions of Albert of Saxony and William of Ockham ${ }^{15}$, one can see a clear tendency shared by most medieval scholars

\footnotetext{
${ }^{13}$ A. de Libera, "La problématique de l'instant du changement," 66. See also N. Kretmann, "Incipit/Desinit"; N. Strobach, The Moment of Change, ch. 3.

${ }^{14}$ See again N. Kretzmann, "Incipit/Desinit;" S. Knuuttila and Lehtinen, "Change and Contradiction," and A. de Libera, "La problématique de l'instant du changement."

${ }^{15}$ See A. de Libera, "La problématique de l'instant du changement," 66.
} 
in the relevant period, to ascribe different temporal limits to permanent and successive entities, respectively. This difference between permanent and successive entities as regards their temporal limits is the crucial element that will allow us to trigger the argument that ultimately leads to the four-dimensional view of persistence.

\section{The argument for four-dimensionalism}

The first part of this paper concluded that standard medieval solutions to the limit decision problem claim that permanent and successive entities have different temporal limits. For example, the so-called common theory claims that permanent entities have both limits closed, whereas successive entities have both limits open. The second part of this paper argues that if permanent and successive entities have different temporal limits, permanent entities are impossible: no thing can be permanent.

I will begin by introducing an objection, moved by Paul Vincent Spade, against theories that claim that permanent and successive entities have different temporal limits (\$2.1). Then I will introduce several recent developments in contemporary metaphysics that will allow us to realize the full scope of Spade's objection ( $§ 2.2$ and $\S 2.3)$. On the one hand, these developments will allow us to circumvent Spade's original objection. However, at the same time, such developments will put us in a position to reinforce Spade's objection in a way that will ultimately lead us to the impossibility of there being permanent entities (\$2.4). I will conclude the section by discussing a possible way out from the reinforced objection, and explain why it is ultimately unsuccessful $(§ 2.5)$.

\subsection{Spade's Objection}

In a paper dedicated to Walter Burley's aforementioned De Primo et Ultimo Istanti, Paul Vincent Spade discusses at length Burley's solution to the limit decision problem. Burley shares the common medieval approach to the problem, and starts with distinguishing between permanent and successive entities in the passage quoted before. He then subscribes to the view according to which successive entities are extrinsically limited at both ends, whereas permanent entities are intrinsically limited at their beginning but extrinsically limited at their end.

In his paper, Spade not only investigates the reasons why Burley may have held such a view, but also engages critically with it by raising a series 
of remarks and objections. One of them is particularly relevant here. In Spade's words:

If every interval of time is a successive entity, as Burley says, and if enduring permanent entities have a first instant of their duration, as he also says, then - despite what Burley explicitly maintains - his theory is unavoidably committed to allowing that at least some successive entities have a first instant of their duration: namely the exact intervals of enduring permanent entities' durations. Although in such a case the thing that fills the time-interval is an enduring permanent entity, the interval of its duration is a successive one, and it is that to which we are assigning limits. No theory can consistently assign limits to temporal intervals in a way different than it assigns them to the durations of things that exactly fill those intervals. But that is just what Burley's theory tries to do. ${ }^{16}$

Spade's objection, in a nutshell, is that Burley's theory leads to a contradiction. For every entity that is in time there should be an instant or interval that counts as its duration, and the entity and its duration should temporally coincide. A permanent entity has its first limit closed. Hence the interval that is its duration should also have its first limit closed. However, given that a duration is an interval of time, it is successive, and hence must have its first limit open.

It is worth noting that the objection as such does not apply to Burley's theory alone. It generalizes to any theory that prescribes permanent and successive entities to have non-coinciding temporal limits, regardless of whether this prescription is made as a consequence of the problem of the instant of change or not. For example, the same objection affects the socalled common theory according to which permanent entities are intrinsically limited at both ends, whereas successive entities are extrinsically limited at both ends.

A crucial premise of Spade's objection is the following one:

(P) For every entity that is in time there is an instant or interval that counts as its duration, and the entity and its duration should temporally coincide,

or, in other words, that the former should begin and end exactly when the latter does and vice versa. The premise seems reasonable. However Spade

${ }^{16}$ P. Spade, "How to Start and Stop," 204. 
does not spend much on discussing it. Are there reasons in favour of it apart from its apparent reasonableness?

Let us have a look at the same problem from another perspective. Burley claims that intervals are open. One could take this as proof that there is no such thing as the interval of the duration of a permanent entity, for such an interval should be closed, but there are no closed intervals. Burley, of course, does not talk about the interval of the duration of a permanent entity; he only talks about a permanent entity having a first and a last instant. So the question is: why think that for every permanent entity there should be an interval that counts as its duration?

Interestingly enough, contemporary philosophers have investigated these questions under a slightly different terminology. Spade's premise concerns the relation between a permanent entity and the interval of time at which it exists, and more generally an entity and the region of a dimension where the entity can be found. Contemporary philosophers have long investigated that relation between an entity and a region where it can be found under the name of location. In the next section, I will introduce some basic findings and principles of the contemporary metaphysics of location that will help us answering the aforementioned questions concerning Spade's premise.

\subsection{The contemporary metaphysics of location}

Contemporary philosophers call location the relation between an entity and a region of a dimension where the entity is present. The term location is probably best suited for the spatial case only, but it is not hard to see that the relation concerning the spatial and the temporal case, if not the same, belong to one and the same family - or so contemporary philosophers think. Accordingly, we will say, for example, that I am located at the region of my office, but also that WWI is located at the twentieth century, and more precisely at a four-year interval between 1914 and $1918^{17}$.

One of the points on which contemporary philosophers insist is that location is ambiguous. Several different senses, or modes, of location can be carefully distinguished and defined. At least six different modes of location have been distinguished so far, but here we will focus on two of them only, which are usually considered the central ones, namely weak and exact location. One the one hand, we say that an entity is weakly

\footnotetext{
${ }^{17}$ See R. Casati and A. Varzi, Parts and Places: The Structures of Spatial Representations (Cambridge, Mass., 1999); R. Casati and A. Varzi, "The Structure of Spatial Localization," Philosophical Studies 82 (1996), 205-239; J. Parsons, "Theories of Location," in Oxford Studies in Metaphysics, Vol. 3, eds. K. Bennett and D. Zimmerman, (Oxford, 2007), 201-232.
} 
located at a region if and only if the region is not completely free of it. In this general sense an entity can be located at several regions of a dimension. Consider for example the image below, depicting a grey entity $x$ and a series of red-dashed regions $r 1-r 5$. The grey entity $x$ is weakly located at regions $r 1, r 2, r 3$ and $r 4$, for all those regions are not completely free of it, but it is not weakly located at region $r 5$, which is completely free of it. On the other hand, we say that an entity is exactly located at a region if and only if $x$ and $r$ have the same shape, size, and stand in the same distance relations with other entities ${ }^{18}$. Looking back at the image below, $x$ is exactly located at $r 1$ only, because $r 1$ is the only region that has its same shape, size, and that stands in its same distance relations with other entities - for example the other regions in the image - in the relevant dimension.

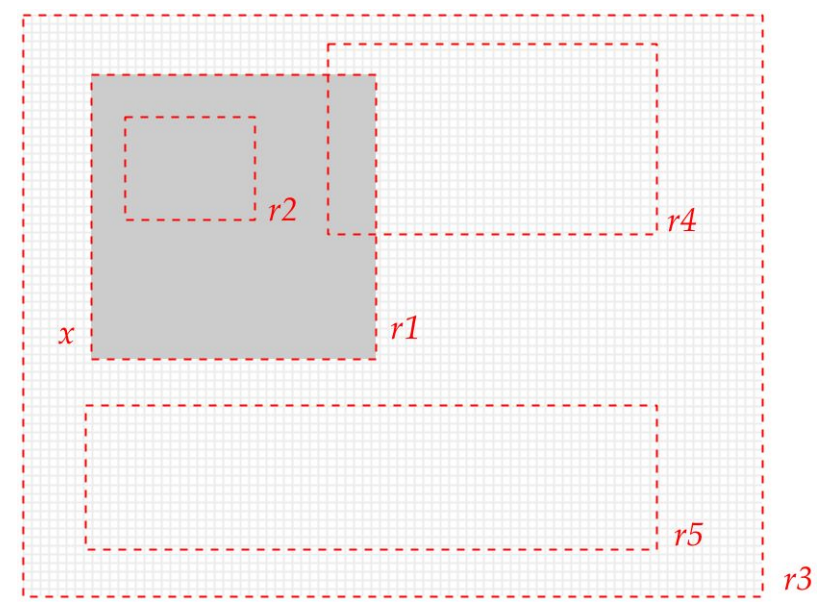

Figure 3. Weak and exact location. The squared grey entity $x$ is weakly located at regions $r 1, r 2, r 3, r 4$, is exactly located only at $r 1$. It is neither exactly nor weakly located at $r 5$.

Having distinguished and informally characterized weak and exact location, one important question that poses itself is: what is the relation between these two modes of location? Because of the conceptual vicinity between the two concepts of location, and because of other important

${ }^{18}$ C. Gilmore, "Where in the Relativistic World Are We?" Philosophical Perspectives 20 (2006), 199-236, C. Gilmore, "Persistence and Location in Relativistic Spacetime," Philosophy Compass 3 (2008), 1224-1254. 
reasons ${ }^{19}$, most philosophers think that in principle one mode should be definable in terms of the other. Probably, the most intuitive option is to take exact location as a primitive and define a weak location as any region which overlaps an exact location ${ }^{20}$. So for example $x$ is weakly located at region $r 4$ because $r 4$ overlaps its exact location $r 1$.

A crucial result that follows from this definition of weak location in terms of exact location is that anything that is weakly located at a region will also have an exact location, for a weak location of $x$ is any region that overlaps with $x^{\prime}$ s exact location. This principle is usually called, for obvious reasons, exactness ${ }^{21}$ :

(E) anything that is weakly located in a dimension must also have an exact location in that dimension.

Could exactness offer the much needed justification for the crucial premise of Spade's objection? At first glance, it seems that it can. Recall that the premise was that an entity and its duration should temporally coincide. The premise seems to rely on the intuition that when an entity is located in time, there should be a region of time which counts as its exact location, and this is exactly what is required by the aforementioned principle of exactness, which therefore, I suspect, was what Spade had in mind.

However things are not so obvious on closer look. Spade's premise does not only require that a permanent entity have an exact temporal location. It also requires that this location be an interval of time. This further requirement cannot properly speaking be derived from exactness, which only requires permanent entities, which are in time, to have at least an exact temporal location, without specifying that that exact temporal location should be an interval. This difference is indeed crucial. But in order to see why it is, we should now introduce some basic notions in the contemporary metaphysics of persistence, and in particular explain how three-dimensionalism is nowadays defined.

\subsection{What is three-dimensionalism?}

Recall that three-dimensionalism is the view according to which substances are not extended through time and persist through time without having temporal parts. Prima facie the definition is somehow puzzling. How is it that something which is not extended through time still occupies, in a certain sense, an interval of time which is extended, namely

${ }^{19}$ See M. Leonard, “Locating Gunky Water and Wine," Ratio 27 (2014), 306-315.

${ }^{20}$ J. Parsons, "Theories of Location," 204.

${ }^{21}$ J. Parsons, "Theories of location," 205. 
the interval of its persistence? An answer to this question can be and has been recently given in light of the advancements in the metaphysics of location presented before.

The basic idea is this. According to three-dimensionalism, substances are not extended through time - they are three-, and not four-, dimensional. If a substance is not extended through time, it cannot be exactly located at intervals of time. This is because intervals of time are temporally extended, and recall that an entity shares shape and size with its exact locations. If a substance is not exactly located at intervals of time, it must be located at instants of time. And it can cover an extended interval of time by being exactly located at each instant that makes up that interval. In other words, the idea is that a three-dimensional entity that persists through time is an entity that persists by being exactly located at several instants of time. In this way it can both be temporally unextended and yet persist through an extended interval of time. Defined in this way, threedimensional entities differ from four-dimensional ones in that fourdimensional entities are extended through time, and hence have a temporally extended interval of time as their exact temporal location ${ }^{22}$. It is worth noting that some philosophers prefer to talk of spatiotemporal instead of merely temporal location. In that case, a three-dimensional entity will cover a four-dimensional spacetime region by being exactly located at several, three-dimensional, instantaneous spacetime regions, whereas a four-dimensional entity will cover the same four-dimensional spacetime region by being exactly located at it. The spatiotemporal approach delivers immediately why three-dimensional entities and fourdimensional entities are called in this way. Recall that an entity shares the shape of its exact location. Three-dimensional entities are located at three-dimensional spacetime regions, and hence have three-dimensional shapes, whereas four-dimensional entities are located at fourdimensional spacetime regions, and hence have four-dimensional shapes $^{23}$.

\footnotetext{
${ }^{22}$ T. Bittner and M. Donnelly, "A Classification of Spatio-temporal Entities Based on Their Location in Space-time," in International Workshop on Semantic-based Geographical Information Systems, ed. E. Zimanyi (Dordrecht, 2006), 1626-1635; T. Sattig, The Language and Reality of Time (Oxford 2006); C. Gilmore, "Where in the Relativistic World Are We?."

${ }^{23}$ C. Gilmore, "Where in the Relativistic World Are We?."
} 

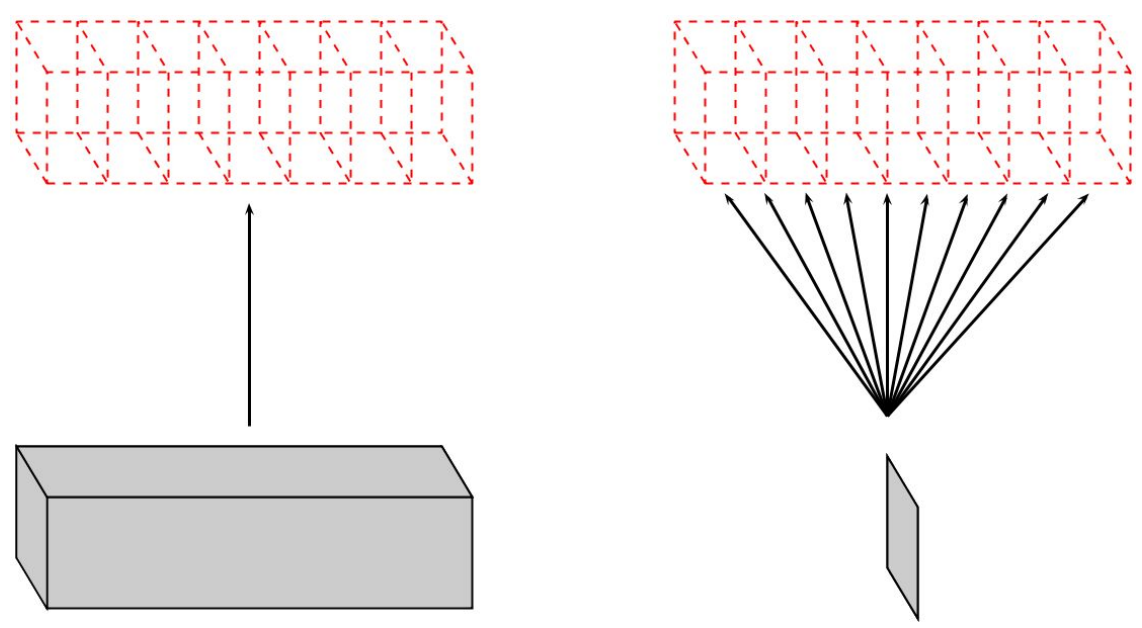

Figure 4. Three- and four-dimensionalism. On the left, a fourdimensional entity occupies a four-dimensional region by being exactly located at it. On the right, a three-dimensional entity occupies a four-dimensional region by being exactly located at several instantaneous regions making up that region.

Now we are in a position to see why a three-dimensionalist can reject Spade's premise and yet keep exactness. First, recall we are working under the hypothesis that permanent simply means three-dimensional. A three-dimensionalist will then reject Spade's premise, because it requires that a permanent - hence three-dimensional - entity is exactly located at an interval, whereas the three-dimensionalist thinks that threedimensional entities are not exactly located at intervals. Yet, in so doing the three-dimensionalist will keep exactness, because three-dimensional entities have indeed exact temporal locations, namely the instants of time that make up the interval of their persistence.

\subsection{Spade's objection reinforced}

In the previous section, we have seen how in light of the recent developments in the metaphysics of location and persistence, Spade's objection - or at least the first reading that I have given to it - can be ultimately resisted. Yet, this does not mean that Spade's objection cannot be reinforced in a way to be successful. In this section, I shall indeed present a reinforced version of Spade's objection which will conclude that if we assign temporal limits to permanent entities in a different way from the one we use for successive ones, a contradiction follows and permanent entities are thus impossible. I shall present the argument as 
an argument directed against the common theory but in principle the argument can be easily adapted to any theory according to which permanent and successive entities have different temporal limits. I will leave to the reader the task of adapting the argument to her or his favorite version of such a theory.

The argument runs as follows. Think again over the duration of a permanent entity. The duration of a permanent entity is an interval of time. It is not the exact location of that entity, because permanent entities are only located at instants and not at intervals. Rather, the duration of a permanent entity should be conceived as the sum of all the instants at which the permanent entity is exactly located ${ }^{24}$.

It can be proven that this sum is an interval of time which is intrinsically limited at both ends. First, let us prove that it is an interval of time. It is, because an interval of time is a sum of instants connected by the order of temporal succession that is limited by two instants and such that any instant that lies between the two limiting instants is also included in the sum $^{25}$. The two limiting instants are the first and last instant of the existence of the permanent entity. And granted that the existence of the permanent entity is not intermittent, all instants that lie in between the limiting instants are also included in the sum. Second, let us prove that this interval of time has both limits closed. An interval of time has both limits closed if and only if the two limiting instants are included in the sum that is the interval ${ }^{26}$. And the limiting instants of a permanent entity are included in that sum, for a permanent entity has a first and a last instant of its existence and hence at which it is exactly located.

Given what we have just said, we can conclude that the interval of time which is the duration of the permanent entity is an interval of time which is closed at both ends. However, since it is an interval of time, it is successive, and hence it is open at both ends. Contradiction.

\subsection{Transcendentist endurantism to the rescue?}

So far we have only considered the form of three-dimensionalism according to which substances persist through time without having temporal parts by being exactly located at several instants of time. Nowadays this is certainly considered the standard form of three-

\footnotetext{
${ }^{24}$ This is indeed one of the six aforementioned modes of location distinguished by contemporary philosophers. Usually, it is called the path of an entity in the given dimension, and is indeed defined as the mereological sum of all the entity's exact locations in that dimension. Cf. C. Gilmore, "Where in the Relativistic World Are We?."

${ }^{25}$ M. C. Gemignani, Elementary Topology (New York, 1990).

${ }^{26}$ M. C. Gemignani, Elementary Topology (New York, 1990).
} 
dimensionalism. However, it is not the only form of three-dimensionalism on the market. There is another way of defining three-dimensionalism that does not require substances to have exact temporal locations. It is the so called transcendentist theory of persistence, or transcendentist endurantism. The transcendentist theory of persistence denies that substances are weakly or exactly located at regions of time. In other words, it denies that the relation between a substance and the times at which it exist is a relation of location. Rather, it defines such a relation in terms of the events and processes in which such a substance participates. Accordingly, the theory claims that for a substance to exist at a time is for it to participate in an event which is weakly located at that time ${ }^{27}$.

The transcendentist theory of persistence is based on various semantic and metaphysical grounds on which I will not focus here. What is important here is rather the question whether conceiving of threedimensionalism, and hence of permanence, in this way will help the three-dimensionalist out of the reinforced objection. The answer to this question is in the negative. According to transcendentist endurantism, substances exist at times if and only if they participate in events that are located at those times. For example, a human being exists at the interval of its persistence because it participates in her or his life, which is a temporally extended event which is located at that interval. Now either events are successive or permanent. If the former, which seems in any case to be the most plausible option, then events would not have a first and a last instant, and so also the life of the human being would not have a first and a last instant. Hence, also the existence of a human being would not have a first and a last instant, given that for a substance to exist at a time is for it to participate in an event located at that time. If the latter, then events would be three-dimensional and located in time, so the view would in any case fall prey to the reinforced objection presented before.

\footnotetext{
${ }^{27}$ A. Giordani and D. Costa, "From Times to Worlds and Back Again: A Transcendentist Theory of Persistence," Thought: A Journal of Philosophy 2 (2013), 210-220; D. Costa, "The Transcendentist Theory of Persistence," The Journal of Philosophy (forthcoming); P. Simons, Parts. A Study in Ontology (Oxford, 1987); P. Simons, "Where is it At? Modes of Occupation and Kinds of Occupant," in Mereology and Location, ed. S. Kleinschmidt (Oxford 2014), 59-68 and B. van Fraassen, An Introduction to the Philosophy of Time and Space (New York, 1970), when similar views, if not the same, are sympathetically discussed.
} 
To sum up, recent advancements in the metaphysics of location and of persistence led us to see that even if Spade's original objection can be resisted, a reinforced version of it is successful, and shows that if the limits of permanent and successive entities are assigned differently, a contradiction follows. When confronted with this results, several options are available. Just to mention one obvious option, a three-dimensionalist could take these results as a reductio ad absurdum of the idea that permanent and successive entities have different temporal limits. However, if one takes seriously the aforementioned medieval theories, and in particular takes seriously: (i) the distinction between permanent and successive entities, (ii) that this distinction parallels the contemporary one between three- and four-dimensional entities, (iii) that the nature of permanent and successive entities require them to have different temporal limits, (iv) that intervals of time are successive entities, then the most obvious conclusion seems to be that permanence, i.e. persistence without temporal parts, is impossible. Moreover, if one takes seriously the idea that (v) there are substances, and that (vi) substances persist through time, the only possible conclusion to draw seems to be that substances persist by being successive entities, i.e. by having different temporal parts at different times. In other words, tenets (i)-(vi) imply the four-dimensional view of persistence.

I conclude by letting the reader decide whether, if confronted with this problem, medieval scholars would rather embrace four-dimensionalism, reject one out of tenets (i)-(vi), or attack my argument in some other interesting way. Moreover, I will not be surprised if some historians of philosophy will think that the meddling of contemporary notions in the medieval lines of reasoning constitutes an inadmissible anachronism that leads us to a fundamentally distorted interpretation of medieval philosophy in general. On the contrary, I hope that the close interaction that I have put at work in this paper will show the impressive possibilities that are open once contemporary and medieval metaphysics are put at work together, and that the case of the phenomenon of persistence through time is an emblematic case of the possibility of this convergence - one that remains, as yet, largely uncharted. 